\title{
Tensiones en la regulación jurídica de la Protección Social en Colombia
}

\author{
Diana Patricia Quintero Mosquera ${ }^{1}$
}

\begin{abstract}
The article explains the tensions in juridical standards of social protection in Colombia. These standards are inscribed in the different regulatory paradigms whose content is defined by the State through its legislative, juridical, and administrative agencies. Based on the evaluation of labor and constitutional experts, the article concludes that these paradigms of social law, in spite of their internal tensions, are those which offer the most satisfactory answers to the needs of the Colombian social, economic and cultural inclusion-especially for the most vulnerable.
\end{abstract}

\section{Introducción}

Para los legisladores, los jueces, los teóricos del derecho, los profesores y estudiantes de las facultades de derecho, cada vez es más necesario estar atentos a lo que las ciencias sociales estudian y discuten sobre los efectos de la normatividad jurídica en la sociedad, sobre lo que esa normatividad decide acerca de la protección social, y sobre sus vacíos al respecto. Lo jurídico no vive de sí mismo ni existe para sí mismo. Sus tensiones no nacen de oposiciones entre principios o conceptos que se engendrarían a sí mismos. Esas tensiones están condicionadas por las muchas formas reales de la "insociable sociabilidad"” que el derecho ha de tener siempre en cuenta y que a veces desencadena.

\footnotetext{
${ }^{1}$ Quiero agradecer los valiosos aportes y comentarios que recibí de Lelio Fernández, Mauricio Lenis, Fernando Gandini y Rafael Silva, profesores de la Facultad de Derecho y Ciencias Sociales.

${ }^{2}$ Kant, Emmanuel, "Idea de una historia universal en sentido cosmopolita” en Filosofía de la historia, ed. Fondo de cultura económica, México, 1991.
} 
Por su parte, los profesionales de la salud y de la educación, los economistas, los sociólogos y los antropólogos han podido comprobar, en estos últimos años, que la protección social es una realidad en el Estado social de derecho proclamado en la Constitución política que nos rige. Por supuesto, todos ellos son también testigos especiales de las limitaciones de esa realidad y de las tensiones importantes que en ella se generan. En algunas páginas inéditas de una colega de Facultad, la antropóloga Inge Valencia, a propósito de su investigación sobre la reconstrucción identitaria de poblaciones negras rurales se afirma que "los cambios legislativos sobre el estatus de esta poblaciones —el reconocimiento jurídico otorgado por varias constituciones latinoamericanas - han suscitado una reconstrucción identitaria en cuyo trasfondo hay una nueva bipolaridad: nación vs comunidad étnica”. No ha de ser sorprendente que esa trasformación dé lugar a nuevas tensiones, como las que presionan y se agitan en la formación de la bipolaridad que señala el texto citado.

La cita ilustra cómo puede ser útil para los profesionales de la intervención social y de las investigaciones propias de las ciencias sociales estar atentos a lo que sucede en el ámbito jurídico y a su incidendia en la realidad social. Desde luego resulta necesario acceder a una adecuada información sobre la regulación jurídica de la protección social de todos los habitantes del país, al menos de sus aspectos básicos. El cuadro normativo es vasto y no siempre es coherente, o completo.

Lo que me propongo es ofrecer en estas páginas un panorama general orientador, que llame la atención sobre las tensiones propias de la normatividad jurídica de la protección social. Para eso, será indispensable comenzar por los sentidos que, en ese cuadro, tiene la expresión: “protección social”. Explicaré esos sentidos como resultado de tres paradigmas de regulación jurídica. Al hacerlo, pondré de manifiesto las principales tensiones que se encuentran en cada uno de esos paradigmas, en su interior y entre ellos. Trataré de contextualizar los cambios introducidos en la regulación de la protección social desde la década de los noventa hasta ahora. Finalmente, reflexionaré sobre el impacto que la acción ciudadana ha tenido sobre la implementación de respuestas institucionales a los problemas de exclusión social. Me propongo evaluar de qué forma cada uno de los tres paradigmas de regulación responde a las exigencias sociales de protección.

La expresión “protección social” tiene en su dimensión jurídica al menos dos sentidos pertinentes. El primero es amplio, según el cual las personas encuentran protección frente a los riesgos sociales, mediante la aplicación o creación de reglas 
constitucionales. Este sentido aunque no es técnicamente usado, se desprende de prácticas jurídicas recientes, que han aportado formas valiosas de proteger a los ciudadanos en sus condiciones de vulnerabilidad. El segundo sentido es más restringido y se circunscribe al campo del tradicional derecho del trabajo y de la seguridad social. Se trata de una parte del derecho privado ${ }^{3}$ que durante algo más de una década ha ampliado sus instituciones clásicas, a fin de incluir nuevos sujetos de protección y nuevas lógicas de funcionamiento.

En ambos se presentan tensiones entre los principios, valores o fines que justifican y sirven de base a la regulación. Las principales se presentan entre la igualdad formal y la igualdad real o material, entre el interés común y el interés particular y entre la autonomía de la voluntad y la solidaridad. Muchas de las dificultades presentes en la regulación y en su puesta en práctica se deben al carácter indeterminado de estos principios. Esta vaguedad o indeterminación hace posible que el poder político le otorgue prioridad a unos u otros indistintamente, los pondere con otros fines sociales como el desarrollo económico, la seguridad y la paz. Esto muestra no solo el carácter político de la regulación, sino que permite entenderla como una herramienta que puede tener, por este hecho, diversos usos políticos.

\section{Las formas constitucionales de la protección social}

Uno de los temas recurrentes en los debates jurídicos de las últimas décadas es la importancia de ampliar las libertades y capacidades individuales, mediante la acción estatal regulatoria y correctora de los problemas que nacen del mercado. Dentro de corrientes actuales de pensamiento jurídico se reconoce que la indiferencia hacia la situación de marginalidad económica, social y cultural de la mayoría de los miembros de la sociedad resulta incompatible con los anhelos de desarrollo económico. El desarrollo relevante y deseable no se ha de entender solo como un objetivo que se deriva del crecimiento económico; ha de ser definido en términos de desarrollo social y humano, -a partir del enfoque del desarrollo humano- para la expansión de las

\footnotetext{
${ }^{3}$ Los laboralistas no coinciden en definir al derecho del trabajo y la seguridad social como un derecho totalmente privado. En ocasiones lo presentan como un derecho mixto, que involucra aspectos públicos y privados. El criterio para la clasificación como derecho público es su carácter obligatorio, impuesto. Y la definición como derecho privado se refiere a la posibilidad que tienen los particulares de definir el contenido de los contratos, así como las relaciones presuntamente voluntarias entre empleadores y empleados.
} 
libertades de la persona. Desde esta perspectiva, las libertades individuales se interpretan como capacidades reales de escoger entre distintas formas de vida posibles. La escogencia supone unas condiciones materiales que liberen al individuo de la zozobra por alcanzar la satisfacción de sus necesidades más básicas, que le permita ampliar la esfera de sus capacidades.

La búsqueda del desarrollo ha llevado a los países latinoamericanos a establecer reformas institucionales que integran de una u otra forma las distintas perspectivas existentes sobre el desarrollo. Muchos Estados, Colombia entre ellos, reformaron las constituciones existentes o crearon otras, como parte de esa búsqueda. La Constitución creada en 1991 fue entendida por muchos sectores como el resultado de algunos acuerdos sustanciales en torno al individualismo imperante, y una respuesta institucional a la necesidad de ampliar los derechos de los individuos. Con ella se habría fortalecido el núcleo liberal, representado por los postulados básicos del laissez faire, tales como la autonomía de la voluntad y la capacidad contractual. ${ }^{4}$ Sin embargo, en el proceso de su creación participaron fuerzas políticas no liberales, que aceptaron el fortalecimiento de los principios liberales individualistas con la condición de definir el Estado bajo la forma social y de establecer un listado de derechos de naturaleza social, económica y cultural. También obtuvieron el reconocimiento de la diversidad cultural, de la igualdad material y de la idea de desarrollo sostenible De esta forma se consagraron en la Constitución disposiciones intervencionistas del mercado, correctivas de sus fallas, que extendieron al ámbito de las relaciones privadas los principios de solidaridad y equidad.

El acuerdo sobre estos aspectos fue puramente formal, tal como expresara el propio presidente Gaviria en el momento de instalación de la Asamblea Nacional Constituyente, al definir el carácter programático, y en esa medida de realización progresiva, de los principios de naturaleza social. ${ }^{5}$ Sin embargo, a partir de ese momento fue un hecho que el Estado quedó obligado a respetar los derechos ciudadanos, tanto los individuales como los sociales, y a “crear mecanismos institucionales esenciales para la realización de los derechos, proteger los derechos e

\footnotetext{
${ }^{4}$ La autonomía de la voluntad es la facultad que tienen los contratantes para llevar a cabo los negocios jurídicos que deseen y en la forma y condiciones que crean convenientes, dentro de los límites que establece el derecho en general. La capacidad contractual es la facultad de los individuos para obligarse por ellos mismos; es más reducida que la primera.

${ }^{5}$ En las Gacetas de la Constituyente se expresa con claridad la multiplicidad de sentidos que se dieron a la expresión "Estado social de derecho", por parte de las fuerzas políticas y sociales presentes. Ideológicamente se la identificó con el social cristianismo, con el liberalismo social, o con el socialismo. La definición de su contenido fue dejada así a la Corte Constitucional.
} 
impedir su violación, proporcionar bienes y servicios para la realización de los derechos, etc.”. ${ }^{6}$ La centralidad de los derechos en el texto constitucional se hizo incompatible con la adopción de disposiciones contrarias a los fines de equidad y de justicia, en la persecución del crecimiento económico. Este crecimiento económico y social impuso al Estado la obligación de liberar a las personas de su condición de vulnerabilidad, combatir la pobreza de capacidades, y ampliar la garantía de los derechos individuales y sociales fundamentales. El instrumento escogido para llevar a cabo estas tareas fue la regulación, como ha sido tradicionalmente.

La protección social adquirió a partir de ese momento un nuevo sentido. No era la primera vez que en Colombia la regulación jurídica se diera a la tarea de concretar disposiciones protectoras de las personas más vulnerables de la sociedad. Los textos de teoría jurídica recuerdan los años de 1936 al 1939, época en que la sala civil de la Corte Suprema de Justicia se dedicó a interpretar el código civil de manera favorable a la entonces denominada “cuestión social”. Esa corte, ‘la Corte de oro”, es quizás el antecedente más importante de la protección social introducida por la Constitución actual. Pero en el esquema institucional hoy vigente, la protección asume distintas definiciones, que se han ido concretando por diversas vías de regulación. La primera se refiere a un sentido no propiamente técnico, según el cual se brinda protección a las personas excluidas de la vida económica, social, cultural del país, a través de mecanismos judiciales o legislativos. Estos mecanismos operan mediante la aplicación directa de la Constitución para responder a las demandas ciudadanas por la satisfacción de necesidades básicas y derechos fundamentales. La primera vía es legislativa, mediante la creación de leyes que otorgan una protección especial a los denominados grupos vulnerables. La segunda, de aplicación directa de la Constitución, ha sido la protección judicial de los derechos fundamentales.

La protección legislativa y judicial

La protección legislativa se concreta en las denominadas leyes de acción afirmativa, también conocidas como leyes de discriminación inversa. En virtud de estas los grupos vulnerables, tradicionalmente discriminados, marginados o perseguidos, han obtenido la

\footnotetext{
${ }^{6}$ Steiner Henry y Alston Phillip, International Human Rights in context: law, politics, and morals, Edit. Oxford University Press, New York, 2000, pp. 182, 184.
} 
expedición de leyes que les otorgan un tratamiento diferenciado, como forma de permitir que la igualdad sea real y efectiva. Ejemplos de estas disposiciones son:

a. la ley 70 de 1993, sobre comunidades negras

b. la ley 82 de 1993, de apoyo especial a la mujer cabeza de familia ${ }^{7}$

c. la ley 324 de 1996, normas a favor de la población sorda

d. la ley 361 de 1997 sobre mecanismos de integración a favor de personas con limitaciones físicas

e. la ley 387 de 1997 de atención y protección a los desplazados

f. la ley 509 de 1999, modificada por la ley 1023 de 2006 sobre beneficios a favor de las madres comunitarias

g. la ley 581 de 2000, equidad en favor de la mujer

h. la ley 649 de 2001 sobre participación política de las minorías étnicas y la ley 691 de 2001, mediante la cual se reglamenta y garantiza el derecho de acceso y la participación de los pueblos indígenas en los servicios de salud

j. la ley 1098 de 2006, ley general de infancia.

Estas leyes, y sus decretos reglamentarios, son desarrollos del artículo 13 de la Constitución, en el que se prohíbe la discriminación excluyente fundada en criterios como la raza, el género, la orientación sexual, etc. Al mismo tiempo, esta disposición impone al Estado el deber de tomar medidas encaminadas a incluir en la vida económica social y cultural a los grupos, comunidades y personas tradicionalmente excluidos. Su existencia ha sido generadora de nuevas realidades, en la medida en que ha hecho visibles las condiciones de marginalidad en que han vivido importantes sectores de la población colombiana. También les abrió la posibilidad de tramitar reclamos simbólicos por el reconocimiento del valor de sus peculiaridades culturales, y demandas económicas o sociales concretas.

La protección judicial se expresa en los siguientes mecanismos:

1. La acción de tutela, para detener las situaciones de peligro o para corregir vulneraciones realizadas por particulares o entidades estatales en contra de los derechos sociales. En especial se han protegido derechos al mínimo vital, la salud, la educación, la seguridad social, el trabajo y la estabilidad laboral, la igualdad de oportunidades, y la diferencia cultural. La tutela también ha sido usada para proteger

\footnotetext{
${ }^{7}$ Por vía jurisprudencial se incluyeron a los padres cabeza de familia.
} 
libertades individuales y derechos sociales a grupos que requieren especial protección, entre los que se encuentran los niños, las personas con discapacidades, las personas con enfermedades catastróficas, de la tercera edad, pensionados, o personas sin capacidad económica que no reúnen los requisitos para obtener la pensión, las madres y los padres cabeza de familia, las mujeres embarazadas, los miembros de comunidades indígenas o grupos tribales.

2. Las acciones de grupo, tramitadas y concedidas por el Consejo de Estado para ordenar a las entidades públicas la protección de derechos colectivos. Esta posibilidad se concretó en fallos tendientes a garantizar el derecho colectivo a la salud pública, ante las amenazas derivadas del incumplimiento estatal de sus obligaciones en la materia.

\section{Paradigmas de regulación de la seguridad social y del trabajo.}

Una segunda forma, más técnica, de entender la protección social es la que comprende el sistema que organiza, en la actualidad, el tradicional ámbito de la seguridad social y el trabajo. A raíz de la creciente importancia del concepto de “manejo social del riesgo"8 nuestro país emprendió recientemente la reforma de su regulación sobre la materia y dio el paso a un nuevo sistema. Su comprensión no es posible sin considerar el paradigma en el que se ubica, así como las relaciones de continuidad y de ruptura con el esquema que le antecede.

Los países latinoamericanos enfrentan importantes tensiones en el ámbito de la regulación jurídica del trabajo, de la Seguridad social y, más actualmente, de la Protección social. De un lado hay quienes consideran que la globalización hace necesario tener un derecho del trabajo y la seguridad social con estándares no muy altos de protección y con modelos flexibles. En esta línea encontramos, a quienes consideran que el reto de Latinoamérica en materia laboral es, por encima de todo, realizar ajustes jurídicos y económicos que atraigan la inversión extranjera, y la generación de empleo, como consecuencia de la creación de posibilidades de mejores utilidades y de inversión para los empresarios. ${ }^{9}$ Desde esta perspectiva se resalta la necesidad de regular para la

\footnotetext{
${ }^{8}$ Véase “Creación del Sistema Social de Riesgo para Colombia” informe final de la Consultoría BID DNP, realizado por el CRECE de Manizales, 2001.

${ }^{9}$ Vgr Lizama Portal, Luis, Presidente de la Sociedad chilena de derecho del trabajo y de la seguridad social. Periódico Ámbito jurídico, No. 179, junio 20 de 2005.
} 
competencia, aceptando las condiciones de una economía de mercado. La labor del Estado se reduce al doble papel de regular y asumir prestaciones de las que no se pueden hacer cargo las empresas privadas.

De otro lado encontramos a quienes abogan sobre todo por la protección cada vez mayor de la población vulnerable en materia de trabajo y seguridad social. El Estado, en atención al principio de Estado social de derecho, debería tener estándares altos en materia de protección social, a fin de mitigar los riesgos personales que producen las fallas del mercado. ${ }^{10}$ La regulación laboral y de seguridad social, al lado de una fuerte protección de los derechos constitucionales de naturaleza social, económica y cultural, son herramientas que hacen posible esa mitigación.

Estas concepciones forman parte, a su vez, de tres paradigmas de regulación jurídica; el primer paradigma, defensor de estándares no muy altos de protección social, es el del derecho privado clásico. A partir de este se afirma la necesaria igualdad formal o igualdad ante la ley, con independencia de las posiciones sociales. La autonomía de la voluntad y la capacidad contractual serían los valores centrales en la relación entre particulares, o entre estos y el Estado.

El segundo, que puede definirse como el paradigma del derecho social, ${ }^{11}$ y el tercero caracterizado por la sociología jurídica como el del derecho regulativo, abogan por altos estándares de protección. Se caracterizarían por ser correctivos de las disfunciones que genera el primero y tendrían entre sus elementos definitorios los siguientes:

a. la tendencia a otorgar tratamientos desiguales a los sujetos ubicados socialmente en diversas posiciones, y la construcción de principios de interpretación favorables a dichos tratamientos desiguales.

b. el establecimiento de limitaciones a la autonomía de la voluntad y a la capacidad contractual, como valores centrales del paradigma del derecho privado, fundadas en el interés común o en valores colectivos.

c. la inclusión, dentro del listado de funciones estatales, de labores de promoción para grupos vulnerables.

El paradigma del derecho social asume formas precisas en la argumentación de base política y social de notables exponentes del denominado constitucionalismo social, y del

${ }^{10}$ Véase Albagli, Elias, "Mercado laboral y crecimiento económico: recomendaciones de política paraC hile, Revista Estudios Públicos 99, Chile, invierno de 2005.

${ }^{11}$ Véase Abramovich, Victor y Courtis Christian Los derechos sociales como derechos exigibles Ed. Trotta, Madrid, 2002. 
derecho regulativo. Según el constitucionalismo social ${ }^{12}$ una forma de pensar las instituciones jurídicas es la postura igualitaria. A partir de esta visión se reclama al Estado un rol más protagónico en la vida social, al asignársele labores de protección de derechos sociales, económicos y culturales. Esta asignación supone la superación de un concepto más estrecho de instituciones jurídicas, centrado en la creencia en el mercado como instrumento fundamental de coordinación social. El Estado, en los procesos de creación y ajuste institucional, no debería ya limitarse a las tareas de asegurar el orden público, garantizar el cumplimiento contractual y proteger los derechos de propiedad.

El derecho regulativo por su parte, es descrito por la sociología del derecho ${ }^{13}$ como un fenómeno jurídico que surge como reacción al Estado liberal clásico, que está vinculado a la idea de un Estado intervensionista o Estado social de derecho. Puede definirse como un proceso de materialización del Derecho, en la medida en que se produce por la introducción de aspectos materiales de tipo político, económico, social y valorativo dentro del derecho. Existen dos versiones del mismo: un derecho regulativo de tipo social y otro económico. Esto tendría su explicación, a mi juicio, en el hecho de que la "primera oleada de instrumentos regulativos" se haya producido en respuesta a demandas de corrección de desequilibrios tanto sociales como económicos.

Una segunda tensión presente en el ámbito de la regulación laboral y de seguridad social se refiere al órgano o a los órganos encargados de regular las relaciones sociales relevantes para estas áreas del derecho. Una visión clásica, dentro del paradigma del derecho privado, deja en manos del Congreso la tarea regulatoria, de manera privilegiada y excluyente. Su explicación y justificación se fundan en el modelo positivista jurídico, según el cual el derecho es una creación del soberano racional, sabio y capaz de anticipar todas las posibles situaciones sociales necesarias de regulación. La segunda visión, propia del derecho regulativo, deja en manos de la rama administrativa del poder público la labor regulatoria. Esto se explicaría en parte por los orígenes mismos del Estado social de derecho, que los teóricos ${ }^{14}$ ubican en la Alemania de finales del siglo XIX, como un proceso de expedición de normas administrativas tendientes a conjurar la situación de crisis económica y social vivida por la población. Y la tercera y última forma de ver el asunto es más el resultado de los tribunales constitucionales y de la llamada constitucionalización del derecho privado. Esta visión

12 UPRIMNY, Rodrigo. et al. Justicia para todos? Sistema judicial, derechos sociales y democracia en Colombia, Grupo editorial norma, Bogotá, 2006, pp. 18 - 29.

${ }^{13}$ Calvo García, Manuel ,Transformaciones del Estadoy del Derecho., Ed. Universidad Extemado de Colombia, Bogotá, 2005.

${ }^{14}$ FORSTHOFF, Ernst. El Estado de la sociedad industrial, Madrid: Instituto de estudios políticos, 1975. 
se justificaría y explicaría a partir de la consideración de los jueces constitucionales como los mejores garantes de los derechos sociales consagrados en los textos constitucionales.

En el caso colombiano esta ultima tensión se evidencia a diario, en particular en las sentencias de la Corte Constitucional que obligan al Estado a pagar cuantiosas indemnizaciones, como resultado de despidos producto del adelgazamiento estatal. ${ }^{15}$ En otras ocasiones se han recocido prestaciones a trabajadores vulnerables cuyos derechos quedaban sin protección, ante la liquidación de una empresa privada, y la existencia del velo societario que impide hacer responsables a los socios, más allá del monto de sus aportes. En estos casos la Corte considera prioritaria la protección del grupo vulnerable, sacrificando la autonomía de la voluntad, o la libertad contractual, principios centrales en el paradigma del derecho privado, expuesto líneas arriba.

El cumplimiento de fines sociales por parte de la administración también puede tener su origen en los mandatos del juez constitucional. Esta rama tiende a desmontar los aparatos estatales que contienen políticas sociales protectoras de los ciudadanos, así como a fusionar ministerios, adelgazar las instituciones públicas, recortarles presupuesto etc. Al mismo tiempo, los jueces constitucionales dan respuestas garantistas a las demandas ciudadanas por protección de sus derechos al trabajo y a la seguridad social. Las respuestas imponen a la administración el deber de tomar medidas, diseñar políticas públicas e implementarlas, a fin de cumplir con los mandatos constitucionales.

La Corte Constitucional ha creado la figura del estado de cosas inconstitucional para revisar todas las actuaciones administrativas en una materia referida a derechos sociales. También ha establecido un mecanismo para hacer seguimientos anuales a dichas actuaciones, con el objeto de hacer que la administración elimine paulatinamente las condiciones que reproducen la vulneración de derechos. El caso más importante que se ha tratado de esta forma es la sentencia sobre desplazados, la T-025 de 2004, en la que se acumularon tutelas presentadas por 1150 núcleos familiares, todos pertenecientes a la población desplazada. Mediante ella la Corte ordenó a las autoridades nacionales y a las territoriales la adopción de correctivos, dentro de la órbita de sus competencias, tendientes a restablecer una multiplicidad de derechos vulnerados a la población

${ }^{15}$ Hace un tiempo fue noticia el hecho de que en virtud de una sentencia de tutela unos 500 ex empleados, padres cabeza de familia, de la antigua Telecom deberían ser reintegrados a la nómina de la empresa. Se anunció que ellos recibirían la convocatoria para presentarse a la empresa y poder recibir el beneficio. Los salarios dejados de percibir, que deberían ser pagados, ascendieron a más de 100.000 millones de pesos. Esta cifra se suma a los 67.000 millones que cuestan los reintegros de 572 madres cabeza de familia, que ganaron una tutela meses antes de este fallo. 
desplazada. Lo interesante de la figura es que cada año la Corte pide informes a las autoridades respectivas sobre los avances en la materia y expide un nuevo fallo, evaluativo de dichos avances.

Es un hecho verificable la existencia de incongruencias entre la regulación que generan las crecientes demandas ciudadanas, formuladas por vía judicial, y la desregulación que asume la administración, dentro de sus políticas de ajuste fiscal. La ampliación progresiva del sistema se ha visto parcialmente truncada, por las presiones del déficit fiscal, a nivel externo, y externamente por las políticas de ajuste trazadas por los organismos internacionales como el Fondo Monetario Internacional y el Banco Mundial. Y sin embargo, la protección judicial creciente de los derechos implicados, y el paso legislativo hacia el concepto más amplio de protección social, han hecho posible una ampliación de la población protegida. En conclusión se puede hablar de una tensión fuerte entre regulación y desregulación, en el derecho constitucional y el derecho de la seguridad social y del trabajo. Pero en el mismo ámbito del derecho constitucional se presenta otra tensión fuerte entre los valores propios del paradigma del derecho privado, y los valores del derecho social o regulatorio. El carácter valioso de ambos tipos de valores, y el carácter mixto del modelo de desarrollo incluido en la Constitución, hace de estas tensiones algo siempre presente y solo ajustable mediante mecanismos judiciales o legales concretos.

Finalmente y con relación a la forma en que opera la regulación, hay que advertir que si bien podría pensarse en el carácter dominante de la desregulación, por la incongruencia antes descrita, lo que se evidencia es una gran explosión de derecho regulativo, que se produce mediante los decretos, las circulares, las resoluciones, los conceptos producidos por la administración. Estas disposiciones, conocidas técnicamente como actos administrativos, son herramientas para dar concreción a las leyes generales en una materia. La tensión fuerte en el esquema del derecho regulativo se expresa entonces en la proliferación de disposiciones administrativas, el incremento de competencias a los órganos de la administración y el adelgazamiento económico y estructural de los mismos. Esta tensión hace del derecho regulativo un mecanismo débil para garantizar la efectiva protección social de los ciudadanos. 
A continuación se recoge en un cuadro lo expuesto hasta aquí.

\begin{tabular}{|c|c|c|c|c|c|}
\hline \multirow{2}{*}{ 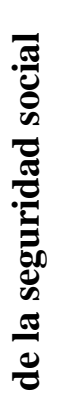 } & $\begin{array}{l}\text { Paradigmas } \\
\text { de } \\
\text { regulación }\end{array}$ & Labor del Estado & $\begin{array}{l}\text { Contenido } \\
\text { del derecho }\end{array}$ & $\begin{array}{l}\text { Valores } \\
\text { centrales }\end{array}$ & $\begin{array}{c}\text { Órganos } \\
\text { encargados }\end{array}$ \\
\hline & \multirow[t]{2}{*}{$\begin{array}{l}\text { Derecho } \\
\text { privado }\end{array}$} & $\begin{array}{c}\text {-Regular para la inversión } \\
\text { privada }\end{array}$ & \multirow[t]{2}{*}{$\begin{array}{l}\text { Estándares } \\
\text { bajos de } \\
\text { protección }\end{array}$} & $\begin{array}{l}\text {-Capacidad } \\
\text { contractual }\end{array}$ & Legislador \\
\hline $\begin{array}{l}\overrightarrow{0} \\
\stackrel{0}{0} \\
.0\end{array}$ & & $\begin{array}{c}\text {-Asumir prestaciones no } \\
\text { privatizables }\end{array}$ & & $\begin{array}{c}\text {-Autonomía } \\
\text { de la } \\
\text { voluntad }\end{array}$ & Administración \\
\hline \multirow{2}{*}{ 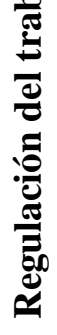 } & $\begin{array}{c}\text { Derecho } \\
\text { social }\end{array}$ & \multirow{2}{*}{$\begin{array}{c}\text {-Mitigar los riesgos } \\
\text { producidos por fallas del } \\
\text { mercado } \\
\text {-Proteger derechos sociales, } \\
\text { económicos y culturales }\end{array}$} & \multirow[t]{2}{*}{$\begin{array}{l}\text { Estándares } \\
\text { altos de } \\
\text { protección }\end{array}$} & \multirow[b]{2}{*}{$\begin{array}{l}\text { Protección } \\
\text { de grupos } \\
\text { vulnerables }\end{array}$} & Administración \\
\hline & $\begin{array}{l}\text { Derecho } \\
\text { regulativo }\end{array}$ & & & & $\begin{array}{c}\text { Juez } \\
\text { constitucional }\end{array}$ \\
\hline
\end{tabular}

Fuente: creación propia.

\section{Las reformas colombianas a partir de la década de los noventa}

A comienzos de los años 90 la agenda del desarrollo se configura en torno a dos propósitos centrales: la internacionalización de la economía y la modernización estatal. Según el discurso político dominante, se trataba de dar el paso hacia la apertura económica como forma de asegurar la inserción del Estado en el mercado internacional. La modernización estatal aparecía como condición básica para su logro. En ese contexto se expidió la ley 50 de 1990, mediante la cual se modificaron aspectos importantes de las partes individual y colectiva del Código Sustantivo de Trabajo. Sus propósitos, según la exposición de motivos, fueron promover la empleabilidad y desarrollar la protección social; fundada en los principios de cooperación y solidaridad. El contenido de la ley flexibilizó la relación laboral, con el propósito de ajustar la legislación interna a las realidades globales del mercado de trabajo. Sus promotores afirmaban que era una respuesta a las consecuencias nocivas que la intervención y el proteccionismo del Estado tenían para los empresarios y para la economía del país en general. Desde el 
comienzo sus críticos la consideraron regresiva, por favorecer los principios de flexibilización laboral, y el recorte de garantías y privilegios a los trabajadores. También se la acusó de atentar contra el ejercicio del derecho de asociación sindical, al dejar en situación de desprotección al trabajador frente a la parte más fuerte de la relación laboral. $^{16}$

Poco tiempo después se aprobó la Constitución de 1991, en la cual se plasmarían los principios que sirvieron de soporte a las reformas sucesivas en la materia. Si bien la regulación sobre la seguridad social y el trabajo corresponde a un ámbito del derecho privado, por encargarse de relaciones surgidas de un contrato de trabajo, en los principios constitucionales se encuentra el marco interpretativo de sus disposiciones. La Constitución también define lo que técnicamente se conoce como los márgenes de acción del legislador; es decir, los límites que el Congreso no puede traspasar al crear o modificar la regulación jurídica en una materia. En ella se encuentran los principios orientadores con relación a la seguridad social, que operan en la vida práctica del derecho.

Su artículo 48, en primer lugar, define la Seguridad Social como un servicio público de carácter obligatorio, que puede ser prestado por el Estado o por particulares bajo la dirección, coordinación y control del primero. Es considerado servicio publico esencial $^{17}$ en lo relacionado con el Sistema General de Seguridad Social en Salud y el de pensiones, sólo en aquellas actividades directamente vinculadas con el reconocimiento y pago de las mismas. En esta disposición quedan asignadas las tareas estatales de coordinación, dirección y control, o prestación directa de los servicios.

Puede leerse indistintamente en el sentido de una apuesta por el modelo de estándares bajos de protección, o por el modelo de estándares altos; esta es una primera tensión que se expresa desde la definición misma de la forma más técnica y tradicional de regulación jurídica de la protección social.

\footnotetext{
${ }^{16}$ Un sector de los laboralistas caracterizó dicha legislación como neoliberal, debido a que, a sus ojos, desreglamentó el mercado de trabajo, atentó contra la estabilidad, al dejar sin soporte el derecho de negociación, fomentó los despidos colectivos, incentivó la violación de la dignidad humana de los trabajadores, y se burló de los convenios de la O.I.T., etc. Ver, Silva Romero, M. Flujos y Reflujos: reseña histórica del derecho laboral colectivo colombiano, Ed. Facultad de Derecho, Ciencias Políticas y Sociales de la Universidad Nacional de Colombia, Bogotá, 2000, Págs. 194 - 207.

17 •"El carácter esencial de un servicio público se predica, cuando las actividades que lo conforman contribuyen de modo directo y concreto a la protección de bienes o a la satisfacción de intereses o a la realización de valores, ligados con el respeto, vigencia, ejercicio y efectividad de los derechos y libertades fundamentales. Ello es así, en razón de la preeminencia que se reconoce a los derechos fundamentales de la persona y de las garantías dispuestas para su amparo, con el fin de asegurar su respeto y efectividad.” Sentencia C-405/95.
} 
La disposición que dio orden a esta regulación, mediante la creación de un sistema, fue la ley 100 de 1993. Sus propósitos están expresados en la exposición de motivos hecha en el Congreso, al momento de su creación:

a. Crear un nuevo sistema pensional basado en el ahorro y capitalización individual, complementado con seguros y garantías estatales

b. Eliminar excesos y equilibrar beneficios, frenando la generación de mayor deuda pensional

c. Extender la protección a la tercera edad excluida, mediante un subsidio

d. Brindar protección temporal a quienes perdiesen su empleo.

Esta ley estableció el sistema de seguridad social integral para toda la población no cobijada por estatutos especiales ${ }^{18}$ de seguridad social. Los objetivos específicos del sistema son garantizar las prestaciones económicas y de salud a aquellos que poseen una relación laboral o capacidad económica para afiliarse al sistema, garantizar la prestación de los servicios sociales complementarios establecidos por ley y garantizar la ampliación de cobertura a toda la población. Sus principios fundantes son los de la Universalidad, la Solidaridad y la Eficiencia. El sistema general se encuentra conformado por tres subsistemas: el sistema general de pensiones, el de seguridad social en salud, el de riesgos profesionales y por los servicios sociales complementarios (SSC): auxilio para ancianos indigentes, SSC para la tercera edad, subsidio al desempleo.

El sistema de seguridad social articulado en la ley 100 está destinado fundamentalmente a proteger a aquella parte de la población que mantiene un vínculo o relación laboral. Aquí opera una primera injusticia, porque con frecuencia se oculta una relación laboral -de continuada subordinación y dependencia- bajo la modalidad de contrato de prestación de servicios. Esto hace precaria la situación del trabajador, al tiempo que le impone las mismas obligaciones de cotización al sistema que las asignadas a los empleados. Hay otras injusticias más evidentes, como las que obligan a cotizar a aquellas personas que no tienen posibilidades reales de cumplir con los requisitos de edad o semanas cotizadas. Son disposiciones que afectan por lo general a las personas de mayor edad. En estos casos se incrementan las condiciones de vulnerabilidad de quienes, en principio, no se encuentran totalmente desprotegidos,

${ }^{18}$ Es decir, excluyó de su ámbito de aplicación al personal de las fuerzas militares y de policía, a los afiliados al fondo nacional de prestaciones sociales del magisterio y a los servidores públicos y pensionados de Ecopetrol. 
pero cuya situación tampoco debería equipararse sin más a la situación de los trabajadores dependientes jóvenes.

El sistema descrito se mantiene en el paradigma de regulación del derecho privado, así lo indican sus objetivos y los derechos que resultan protegidos. Sin embargo, hay algunos aspectos que obligan a matizar esta caracterización general. En primer lugar, la creación del régimen subsidiado para salud incrementó los niveles de cobertura del sistema y extendió la protección a las personas vulnerables por su falta de capacidad de pago y de trabajo. También la extensión de la protección a las personas no trabajadoras desbordaría los márgenes de este paradigma de regulación, de no ser porque la protección es aun incipiente, establecida mediante subsidios, o dádivas y no como derechos objetivamente exigibles.

En el 2002 se expidió una nueva ley, la 789, que estableció un sistema de protección social, definido en el artículo primero de esta disposición, como el conjunto de políticas públicas establecidas para garantizar a la totalidad de la población y en especial a los miembros de grupos vulnerables, los derechos sociales mínimos: derecho a la salud, a la pensión, al trabajo. El sistema está conformado por las políticas de salud, vivienda, educación, nutrición, empleo o trabajo y recreación.

Una disposición posterior sobre el mismo sistema, el decreto ley 205 de 2003, lo define como el conjunto de obligaciones, instituciones públicas, privadas y mixtas, normas, procedimientos y recursos públicos y privados destinados a prevenir, mitigar y superar los riesgos que afectan la calidad de vida de la población. En cuanto a su integración, el sistema de protección social es más amplio: cobija, además del sistema de seguridad social integral, al sistema nacional de bienestar familiar, al régimen del subsidio familiar y los específicamente asignados al Ministerio de la Protección Social. Funciona mediante subsidios. Sus críticos afirman que se trata de un sistema demasiado amplio, que ha aglutinado prestaciones de naturaleza diversa, que no logran tener coherencia y cuyo funcionamiento depende en buena medida de un ministerio con problemas de funcionamiento.

Una de las reformas más recientes introducidas al sistema se hizo por la vía de la reforma a la Constitución, mediante el acto legislativo No. 1 de 2005. La principal preocupación de esa reforma fue de naturaleza económica, lo que se evidencia en las disposiciones declarativas contenidas en ella:

a. El Estado asegura la sostenibilidad financiera del sistema pensional 
b. Prohíbe el congelamiento, no pago o reducción de las mesadas pensionales

c. Prohíbe el establecimiento -mediante convenciones colectivas, laudos, etc. - de condiciones distintas a las del Sistema General de Pensiones

d. Condiciona el derecho a la pensión únicamente a las leyes del Sistema General de Pensiones

La primera reforma al sistema general de Seguridad Social es un intento por pasar del paradigma de regulación de derecho privado al paradigma del derecho regulativo. Es por esto que sus disposiciones se concretan en múltiples actos administrativos, es decir, decretos, circulares, resoluciones, conceptos de los entes administrativos competentes en materia de protección social. La segunda se inspira más en consideraciones económicas de sostenibilidad, con lo que se vuelve al paradigma del derecho privado. En ella se privilegian las relaciones contractuales entre prestadores y usuarios. Estos no son pensados como habitantes con derechos, sino como consumidores, que deben acudir a las vías judiciales como la tutela para obtener beneficios extracontractuales. En ese proceso se incurre en excesos, tanto del lado de los prestadores como de los usuarios, y la regulación aún no logra prevenirlos o en el mejor de los casos disminuir sus efectos nocivos.

\section{Reflexiones sobre la actuación del Estado social de derecho en Colombia.}

Los asuntos vinculados a la protección social son un aspecto muy sensible en una sociedad con problemas de desempleo, conflicto armado, inestabilidad institucional y exclusión social. Constituyen un ámbito en el que los conflictos son un fenómeno constante, que en materia jurídica se enfrentan mediante la introducción de reformas a las leyes vigentes, la creación de disposiciones administrativas o la producción de reglas judiciales. La presión de la población para asegurar la protección de los derechos ha impuesto pautas de acción al Estado, que no siempre encuentran igual respuesta por parte de todos los órganos del poder público. En general, mientras la legislación es percibida como regresiva e ineficaz, las contribuciones judiciales, en especial las constitucionales, se valoran como progresistas, rápidas y eficaces. Una hipótesis plausible sobre el trabajo judicial de protección es que en la sociedad colombiana la 
estructura básica de la sociedad se hace más explícita a través de las decisiones judiciales, que mediante las disposiciones legislativas o administrativas. Las decisiones judiciales responden a demandas expresadas como resultado de un nuevo tipo de ciudadanía que recurre a la vía judicial para obtener la satisfacción de sus necesidades materiales básicas. Tal satisfacción es asumida como una facultad subjetiva, es decir directamente exigible, no sujeta a las cuestiones de política macro económica, o a los ajustes que los problemas de déficit fiscal imponen a los Estados periféricos.

Algunos críticos del recurso a la vía judicial para la labor protectora consideran que el trabajo de la Corte constitucional, al no tener sustento en un pacto político, en vez de resolver los conflictos los profundiza, generando inestabilidad e incertidumbre. ${ }^{19}$ Esta actitud, se argumenta, por loable que sea desde el punto de vista de coherencia con el Estado social, implica un sacrificio del principio democrático. Según esta visión, las definiciones de política pública deben basarse en el consentimiento y delegación de los ciudadanos, por lo que sus canales legítimos serían los poderes legislativo y administrativo. Sin dicho consentimiento se socavarían las bases mismas de la organización política que se pretende defender. Este fenómeno explicaría, en parte, las hondas polémicas que en el seno de la sociedad y el Estado suscita cada fallo emitido en desarrollo del Estado social. Las críticas más fuertes provienen por lo general del poder ejecutivo o administrativo y de los gremios económicos, quienes argumentan la superioridad de los cálculos costo-beneficio, sobre la efectividad de los derechos fundamentales. Pero al provenir de la iniciativa ciudadana, las decisiones judiciales que imponen al Estado cargas prestacionales quedan revestidas de legitimidad.

Las características del Estado social de derecho, y la actividad de una ciudadanía consciente del carácter exigible de sus derechos sociales fundamentales, otorgan cada vez mayor vigencia a la regulación jurídica de la protección social, promovida bajo el paradigma del derecho social. El paradigma del derecho regulativo aún no logra demostrar, al menos no del todo, sus potencialidades sociales; mientras que el paradigma del derecho privado ha demostrado sus límites e insuficiencias en materia de protección social.

\section{Bibliografía}

\footnotetext{
${ }^{19}$ Un ejemplo de ello se expresa en la inestabilidad de tipo económico que han generado recientes fallos de la Corte Constitucional, relativos a la reglamentación de las políticas de vivienda, mediante los cuales se desmontó el sistema de financiación anterior, denominado sistema UPAC.
} 
Abramovich, Victor y Courtis, Christian, Comp., Derechos sociales Instrucciones de uso, Editorial Doctrina jurídica contemporánea, México 2003, pp. 23 a 50.

Albagli, Elias, "Mercado laboral y crecimiento económico: recomendaciones de política para Chile”, Revista Estudios Públicos 99, Chile, invierno de 2005.

Amin, Samir, El capitalismo en la era de la globalización, Editorial Paidós, Barcelona 1999.

Calvo Garcia, Manuel, Transformaciones del Estado y del Derecho, Editorial Universidad Externado de Colombia, Bogotá, 2005.

Cepeda, Manuel, et al, Derecho Constitucional perspectivas críticas, Siglo del hombre Editores, Santafé de Bogotá, 1999.

Forsthoff, Ernst, El Estado de la sociedad industrial, Instituto de estudios políticos, Madrid, 1975.

Kant, Emmanuel, “Idea de una historia universal en sentido cosmopolita”, en: Filosofía de la historia, editorial Fondo de Cultura Económica, México, 1991.

Lee, Hedí, "Mundialización y normas del trabajo. Puntos del debate”, OIT Revista internacional del trabajo, Vol 116, número 2, 1997.

López Garavito, Luis Fernando, Pensamiento económico y fiscal colombiano, Editorial Universidad Externado de Colombia, Santafe de Bogotá 1998.

Marshall, T.H. y Bottomore, T. Ciudadanía y clase social, Madrid, Editorial Alianza, Madrid, 1998.

Novoa, Armando, Empleo, desempleo y reforma laboral: un tema indispensable en la agenda para la paz, Mandato ciudadano por la paz y la vida, Bogotá 1999.

Pérez Luño, Antonio, Derechos Humanos, estado de Derecho y Constitución, Editorial Técnos, Madrid, 1995.

Rawls, John. Political Liberalism, Colombia U. Press, N.Y., 1993.

, Teoría de la Justicia, F.C.E., México, 1995.

Restrepo Botero, Darío, "El mito de Sísifo o veinte años de pujanza descentralizadora en Colombia”, en: Revista del CLAD Reforma y Democracia, No. 17, Junio de 2000.

Romero, M., Flujos y reflujos: reseña histórica del derecho laboral colectivo colombiano, Editorial de la Facultad de Derecho, Ciencias Políticas Y Sociales de la Universidad Nacional de Colombia, Bogotá, 2000.

Sánchez Ferriz, Remedio, Introducción al Estado constitucional, Editorial Ariel, Barcelona, 1993. 
Sastre, Rafael, El derecho al trabajo, Editorial Trotta, Madrid, 1996.

Sterba, James, Justice: Alternative political perspectives, Wadsworth publishing company, Belmont, 1991.

Steiner, Henry y Alston, Phillip, International Human Rights in context: law, politics, and morals, Edit. Oxford University Press, New York, 2001, pp. 182, 184.

Uprimny, Rodrigo, et al, ¿Justicia para todos? Sistema judicial, derechos sociales y democracia en Colombia, Grupo editorial Norma, Bogotá, 2006, pp. 18 - 29.

http://www.fundacionpobreza.cl/fnp_biblioteca.asp?Id_Carpeta=334\&Camino=334\%7 CEmpleo 